\title{
Ganho de peso vivo e fermentação ruminal em novilhos mantidos em pastagem cultivada de clima temperado e recebendo diferentes suplementos
}

\author{
Live weight gain and ruminal fermentation by steers grazing cool-season grass \\ pasture and given different supplements \\ Magali Floriano da Silveira² ${ }^{2}$ Gilberto Vilmar Kozloski ${ }^{1}$ Ivan Luiz Brondani ${ }^{2}$ \\ Dari Celestino Alves Filho ${ }^{2}$ João Restle ${ }^{3}$ Daniel Terra Leite ${ }^{2}$ \\ Patrícia Alessandra Meneguzzi Metz ${ }^{2}$ \\ Sales Ramiro Lopes da Silveira²
}

\section{RESUMO}

Foram conduzidos dois experimentos para avaliar o ganho de peso vivo (Experimento 1) e parâmetros da fermentação ruminal (Experimento 2) em quarenta novilhos cruzados Charolês e Nelore, mantidos em pastagem cultivada de inverno, por quatro horas diárias e não suplementados, ou por somente duas horas, mas suplementados (1\% do peso vivo) com silagem de planta inteira, silagem de grão úmido ou com grão seco de sorgo. Os animais alimentados somente com pastagem obtiveram os maiores ganhos de peso vivo $(P<0,05)$ e os suplementados com silagem de planta inteira, os menores. Os suplementados com grãos, tanto secos como na forma de silagem, obtiveram ganhos de peso intermediários. As concentrações de aminoácidos e peptídeos não foram influenciadas $(P>0,05)$ pela suplementação, as de amônia $e$ açúcares foram maiores nos animais mantidos somente com pastagem e nos suplementados com silagem de grão úmido, $e$ menores nos animais suplementados com silagem de planta inteira ou com grão seco de sorgo $(P<0,05)$. Os valores de $p H$ ruminal foram menores nos animais suplementados com silagem de grão úmido de sorgo $(P<0,05)$. Os suplementos utilizados não melhoraram o desempenho dos animais mantidos em pastagem cultivada de clima temperado, mas a fermentação ruminal variou ao longo do dia e com o tipo de suplemento utilizado. No entanto, os resultados indicam também que, além do tipo, a adequação de horários de pastejo e de suplementação poderia representar um fator condicionante à eficiência do uso do suplemento pelos animais.

Palavras-chave: aveia, azevém, bovinos de corte, grão de sorgo, silagem de sorgo, suplementação.

\section{ABSTRACT}

Two experiments to evaluate daily weight gain (Experiment 1) and ruminal fermentation parameters
(Experiment 2) were carried out. Nelore and Charolais crossbreed steers grazing on cool-season pasture during four hours daily or during only two hours daily but supplemented (1\% of live weight) with sorghum whole plant silage, wet grain silage or dry grain were used. Animals fed only with pasture obtained the highest and, those supplemented with whole plant silage, the lowest daily weight gain $(P<0.05)$. Wet or dry grain supplemented steers obtained intermediary daily weight gain. Ruminal concentrations of amino acids and peptides were not affected $(P>0.05)$ by supplementation. Ammonia and sugar concentrations were higher by animals fed only with pasture or supplemented with sorghum wet grain silage and lower by those supplemented with whole plant silage or dry grain $(P<0.05)$. Ruminal $p H$ values were lower by animals supplemented with sorghum wet grain silage $(P<0.05)$. Supplements did not improve weight gain of steers grazing cool-season pasture but ruminal fermentation varied through a day and was different among supplements. Results also indicate that, besides supplement type, synchrony between grazing and supplementation schedule may represent a conditioning factor to improve feed efficiency use by animals.

Key words: oat, ryegrass, beef cattle, sorghum grain, sorghum silage, supplementation.

\section{INTRODUÇÃO}

A utilização da forragem pelos ruminantes depende da atividade microbiana ruminal, a qual é dependente, por sua vez, de uma concentração mínima de amônia (SATTER \& SLYTER, 1974), do tipo e quantidade de carboidratos disponíveis (RUSSEL et. al., 1992) e pode ser incrementada pela presença de aminoácidos e peptídeos no fluído ruminal. Além disso,

${ }^{1}$ Departamento de Zootecnia, Universidade Federal de Santa Maria (UFSM), Campus Camobi, 97105-900, Santa Maria, RS, Brasil.

Email: kozloski@smail.ufsm.br. Autor para correspondência.

${ }^{2}$ Departamento de Zootecnia, UFSM, Santa Maria, RS, Brasil.

${ }^{3}$ Departamento de Zootecnia, Universidade Federal de Goiás, Goiânia, GO, Brasil. 
a fermentação ruminal é sensível também às variações do $\mathrm{pH}$ do meio (MOULD \& ORSKOV, 1983).

A concentração de amônia e aminoácidos, assim como o pH ruminal, variam com o tempo após a alimentação e dependem do tipo de dieta. Dietas com maior teor de carboidratos não estruturais tendem a diminuir o $\mathrm{pH}$ e, de outra forma, maiores teores de nitrogênio $(\mathrm{N})$ não protéico ou proteínas solúveis tendem a aumentar o teor de amônia e aminoácidos no fluído ruminal (RUSSEL et al., 1992).

Pastagens cultivadas de aveia e azevém são a principal alternativa forrageira utilizada na região Sul do Brasil, durante o inverno e a primavera. Gramíneas anuais de inverno normalmente têm alta digestibilidade, mas também altos teores de $\mathrm{N}$ degradável, o que pode levar a perdas significativas de $\mathrm{N}$ na urina. Sendo assim, a presença no rúmen de maior proporção de carboidratos não estruturais por meio da suplementação energética poderia aumentar a eficiência do uso de $\mathrm{N}$ da pastagem e melhorar o desempenho dos animais.

A suplementação de animais em pastejo é uma prática usual em muitos sistemas de produção de bovinos, sendo normalmente realizada com concentrados à base de grãos secos, os quais tendem a onerar o sistema. Uma alternativa para a redução de custos seria a utilização de silagem de grão úmido de cereais, que pode ser produzida e armazenada na propriedade e é menos influenciada pela variação de preços do mercado (CHALKING \& BRADESCO, 1997). De outra forma, a silagem da planta inteira de cereais, como o sorgo, tem custo menor que os concentrados e, assim, poderia ser uma alternativa para suplementação de animais mantidos em gramíneas temperadas.

Desse modo, este estudo foi conduzido para avaliar o ganho de peso vivo e parâmetros da fermentação ruminal em novilhos mantidos em pastagem cultivada de inverno não suplementados, ou suplementados com silagem de planta inteira, silagem de grão úmido ou com grão seco de sorgo.

\section{MATERIAL E MÉTODOS}

O estudo foi realizado no Laboratório de Bovinocultura de Corte, do Departamento de Zootecnia da Universidade Federal de Santa Maria, no período de 27 de julho à 28 de setembro de 2003. Foram conduzidos dois experimentos para avaliar o ganho de peso vivo (Experimento 1) e parâmetros da fermentação ruminal (Experimento 2) em novilhos cruzados Charolês e Nelore, com 10 a 11 meses de idade, mantidos em pastagem cultivada de aveia preta (Avena strigosa) e azevém (Lolium multiflorum), por quatro horas diárias e não suplementados, ou por somente duas horas, mas suplementados (1\% do peso vivo, base matéria seca (MS)) com silagem de planta inteira, silagem de grão úmido ou com grão seco de sorgo (híbrido AG 2005E).

A implantação da pastagem foi realizada pelo sistema de plantio direto sobre resíduo de lavoura no dia 12 de maio de 2003. Foram utilizados $40 \mathrm{~kg}$ de semente de azevém e $80 \mathrm{~kg}$ de semente de aveia por hectare, juntamente com uma adubação de base de 430kg de NPK da fórmula 08-10-08 distribuídos na linha. Adicionalmente, ao longo do experimento, foram realizadas três aplicações de uréia em cobertura $(60 \mathrm{~kg}$ ha-1 aplicação-1).

O Experimento 1 foi conduzido em três períodos de 21 dias, com 36 animais, em um delineamento experimental inteiramente casualizado. Todos os animais eram conduzidos à pastagem pela manhã, onde permaneciam por duas horas. Após, eram conduzidos ao curral de espera, onde, às 14 horas, recebiam o suplemento. Neste mesmo horário, os animais não suplementados retornavam para a pastagem por mais duas horas. À noite, todos eram recolhidos e mantidos numa área de repouso provida de água e sal mineral à vontade. Ao final de cada período, os animais foram submetidos a um jejum de aproximadamente 14 horas, pesados e avaliados em relação à sua condição corporal. Para tal, dois avaliadores utilizaram uma escala visual de 1 a 5 , sendo 1 muito magro e 5 muito gordo, conforme LOWMAN et al. (1973). Adicionalmente, em cada período, amostras da pastagem foram coletadas por simulação de pastejo.

O Experimento 2 foi conduzido com quatro animais adicionais, submetidos ao mesmo manejo e alimentação dos animais do Experimento 1, mas implantados com sondas permanentes no rúmen. Foram utilizadas sondas nasais descartáveis siliconizadas nํ24, com aproximadamente $50 \mathrm{~cm}$ de comprimento. A pele e a parede do rúmen foram inicialmente transfixados com uso de um trocarte. A seguir, foi introduzido um guia de aço através do trocarte, o qual então foi retirado e a sonda colocada no rúmen ao longo do guia. Logo após, o guia foi retirado e a pele foi fixada à parede ruminal com dois pontos (fio de náilon) laterais ao ponto de inserção da sonda, junto aos quais foi também fixada a parte externa da sonda. O experimento foi então conduzido em um delineamento Quadrado Latino $4 \times$ 4, em dois períodos iniciais de 15 dias e em dois períodos finais de oito dias. A redução dos últimos dois períodos foi devido a mudanças no estágio de crescimento da pastagem, que passava do vegetativo para o reprodutivo. Nos dois primeiros períodos, amostras de líquido ruminal ( $\pm 30 \mathrm{ml}$ ) foram coletadas, a partir do $11^{\circ}$ 
dia, a cada 8 horas, avançando duas horas a cada dia, obtendo-se amostras a cada duas horas ao longo de um período de 24 horas. Nos últimos dois períodos experimentais, foram coletadas amostras a cada duas horas, durante o último dia de cada período. Imediatamente após a coleta, foi medido o pH e duas alíquotas (4,5ml) foram acidificadas, uma com $0,5 \mathrm{ml}$ de ácido sulfúrico a $20 \%$, e outra com $0,5 \mathrm{ml}$ de ácido tricloroacético (TCA) a 50\%, centrifugadas $(1000 \times$ g) durante 20 minutos e congeladas para posterior análise.

Para análise, as amostras da pastagem e dos suplementos foram secados a $55^{\circ} \mathrm{C}$, em estufa ventilada, e moídas (peneira de $1 \mathrm{~mm}$ ). Foram determinados os teores de MS por secagem em estufa a $105^{\circ} \mathrm{C}$, durante, pelo menos, oito horas; de matéria orgânica (MO), por queima em mufla a $550^{\circ} \mathrm{C}$, por duas horas; de $\mathrm{N}$ total (método 984.13, AOAC, 1995, modificado conforme descrito por KOZLOSKI et. al., 2003); de extrato etéreo por extração com éter a $180^{\circ} \mathrm{C}$, por duas horas; fibra em detergente neutro (FDN), de fibra em detergente ácido (FDA) e de lignina em detergente ácido (LDA; ROBERTSON \& VAN SOEST, 1981); e de N insolúvel em detergente neutro (NIDN) e em detergente ácido (NIDA; LICITRA et al, 1996). A composição química dos alimentos é apresentada na tabela 1 . O teor de nutrientes digestíveis totais dos alimentos foi estimado com base em sua composição química, utilizando-se as equações de WEISS et al. (1992).

Nas amostras de fluído ruminal, foram determinados os teores de $\mathrm{N}$ amoniacal (WEATHERBURN, 1967), de açúcares solúveis (DUBOIS et al, 1956), de aminoácidos e de peptídeos
(PALMER \& PETERS, 1969). Para determinação dos peptídeos, uma alíquota de $1 \mathrm{ml}$ de fluído ruminal foi submetida à digestão ácida com um mesmo volume de $\mathrm{HCl} 6 \mathrm{~N}$ em um tubo de vidro com tampa de rosca, durante 24 horas, em autoclave a $110^{\circ} \mathrm{C}$. A seguir, a solução foi transferida para um balão de $10 \mathrm{ml} \mathrm{e}$ completado o volume com $\mathrm{NaOH} 0,75 \mathrm{~N}$. O teor de peptídeos foi calculado como a diferença entre o teor de aminoácidos no fluido hidrolisado e no não hidrolisado.

Os dados foram submetidos à análise de variância e as médias comparadas pelo Teste de Tukey a 5\% de probabilidade do erro Tipo I. No Experimento 1 , o modelo incluiu os efeitos dos tratamentos, dos períodos e da sua interação e, no Experimento 2, os efeitos dos animais, períodos, tratamentos, tempo e interação tempo $\times$ tratamento. Adicionalmente, os parâmetros ruminais foram analisados por regressão em relação ao tempo de coleta das amostras. Todas as análises foram realizadas utilizando-se o programa estatístico SAS (1996).

\section{RESULTADOS E DISCUSSÃO}

Não houve efeito da interação entre tratamentos e períodos sobre o desempenho dos animais $(\mathrm{P}>0,05)$ e, deste modo, na tabela 2 , são apresentados os resultados médios dos três períodos. Os pesos inicial e final foram similares $(\mathrm{P}>0,05)$, mas os animais alimentados somente com pastagem obtiveram os maiores ganhos de peso vivo $(\mathrm{P}<0,05)$ e os suplementados com silagem de planta inteira, os

Tabela 1 - Composição química ${ }^{1}$ das amostras de pastagem e dos suplementos fornecidos aos novilhos.

\begin{tabular}{llccc}
\hline & & \multicolumn{3}{c}{ Suplementos (sorgo) } \\
\cline { 3 - 5 } Componente & Pastagem $^{2}$ & Silagem da planta inteira & Silagem de grão úmido & Grão seco \\
\hline MS (\%) & 21,10 & 33,3 & 65,44 & 84,92 \\
\hline Composição (\% da MS): & & & & 95,22 \\
MO & 89,73 & 93,54 & 92,18 & 0,99 \\
N & 2,91 & 0,81 & 1,02 & 4,94 \\
EE & 5,02 & 3,89 & 5,57 & 9,71 \\
FDN & 40,17 & 50,40 & 6,87 & 4,23 \\
FDA & 26,54 & 36,39 & 3,60 & 1,86 \\
LDA & 3,86 & 5,80 & 1,50 & 0,18 \\
NIDN & 0,77 & 0,29 & 0,17 & 0,07 \\
NIDA & 0,10 & 0,10 & 0,07 & 88,40 \\
NDT & 70,61 & 72,28 & 86,60 & \\
\hline
\end{tabular}

${ }^{1}$ MS, matéria seca; MO, matéria orgânica; N, nitrogênio total; EE, extrato etéreo; FDN, fibra em detergente neutro; FDA, fibra em detergente ácido; LDA, lignina em detergente ácido; NIDN, N insolúvel em detergente neutro; NIDA, N insolúvel em detergente ácido; NDT, nutrientes digestíveis totais.

${ }^{2}$ Aveia + azevém 
Tabela 2 - Peso inicial, peso final, escore corporal inicial (ECI) e final (ECF) e ganho médio diário (GMD) de novilhos pastejando aveia + azevém não suplementados ou suplementados com silagem de planta inteira, silagem de grão úmido ou grão seco de sorgo ${ }^{1}$.

\begin{tabular}{llllc}
\hline & & \multicolumn{3}{c}{ Suplementos (sorgo) } \\
\cline { 3 - 5 } Variáveis de desempenho & Pastagem & Silagem de planta inteira & Silagem de grão úmido & Grão seco \\
\hline Peso Inicial, kg & 129,3 & 130,4 & 131,0 & 131,0 \\
Peso final, kg & 160,1 & 147,3 & 156,0 & 155,0 \\
ECI, pontos & 2,93 & 2,83 & 2,94 & 2,84 \\
ECF, pontos & $2,90^{\mathrm{AB}}$ & $2,79^{\mathrm{B}}$ & $3,02^{\mathrm{A}}$ & $2,81^{\mathrm{B}}$ \\
GMD, kg/dia & $0,525^{\mathrm{A}}$ & $0,282^{\mathrm{B}}$ & 0,22 & 0,29 \\
\hline
\end{tabular}

${ }^{1}$ Médias seguidas de letras diferentes na mesma linha diferem pelo teste de Tukey ao nível de 5\% de probabilidade do erro Tipo 1.

${ }^{2}$ Desvio padrão das médias, onde $\mathrm{n}=9$ por tratamento.

menores. Os suplementados com grãos, tanto secos como na forma de silagem, obtiveram ganhos de peso intermediários. BRONDANI et al. (2003), por sua vez, verificaram que o ganho de peso de vacas de descarte mantidas em pastagem cultivada de inverno não foi influenciado pela suplementação energética. Esta discrepância de resultados pode estar associada a diferenças nas exigências nutricionais dos animais. As exigências de proteína são mais altas nos novilhos que nas vacas. Uma vez que os teores de proteína dos suplementos foram inferiores ao da pastagem, é provável que o consumo deste nutriente nos animais suplementados tenha sido limitante ao ganho de peso dos novilhos, mas não das vacas.

A condição corporal final refletiu a variação do ganho de peso dos novilhos, sendo melhor nos que receberam somente pastagem ou suplementação com grão úmido $(\mathrm{P}<0,05)$ e pior nos que receberam grão seco e silagem de planta inteira de sorgo.

As concentrações de aminoácidos e peptídeos não foram influenciadas $(\mathrm{P}>0,05)$ pela suplementação (Tabela 3). Já as de amônia e açúcares foram superiores nos animais mantidos somente com pastagem e nos suplementados com silagem de grão úmido e inferiores nos animais suplementados com silagem de planta inteira ou com grão seco de sorgo $(\mathrm{P}<0,05)$. Os animais não suplementados provavelmente consumiram maiores quantidades da pastagem, cujo teor de proteína é bem superior aos suplementos (Tabela 1). VANZANT et al. (1990) observaram que o $\mathrm{pH}$ ruminal de novilhos de corte em pastejo declinou linearmente com o aumento da suplementação com grãos de sorgo, mas CATON \& DHUYVETTER (1997) revisaram dados de pesquisa e verificaram que a suplementação de animais em pastejo com grãos normalmente não implica significativa queda do $\mathrm{pH}$ ruminal. No presente experimento, os valores de $\mathrm{pH}$ (Tabela 3) foram menores nos animais suplementados com silagem de grão úmido de sorgo $(\mathrm{P}<0,05)$. Isso provavelmente foi devido ao baixo $\mathrm{pH}$ inerente aos materiais ensilados e à mais alta disponibilidade de açúcares às bactérias ruminais, cuja fermentação resulta na produção de ácidos graxos voláteis. Comparado a outros cereais, o amido do grão seco de sorgo tem baixa solubilidade e degradabilidade ruminal (ZEOULA., et al, 1999), mas é possível que a ensilagem deste material úmido tenha alterado estas propriedades.

Tabela 3 - Concentração de amônia, aminoácidos, açúcares, peptídeos e pH ruminal de novilhos pastejando aveia + azevém não suplementados ou suplementados com silagem de planta inteira, silagem de grão úmido ou grão seco de sorgo ${ }^{1}$.

\begin{tabular}{lcccc}
\hline & & \multicolumn{2}{c}{ Suplementos (sorgo) } \\
\cline { 3 - 5 } Variáveis ruminais & Pastagem & Silagem de planta inteira & Silagem de grão úmido & Grão seco \\
\hline Amônia, mg/dl & $11,8^{\mathrm{AB}}$ & $9,0^{\mathrm{B}}$ & $12,6^{\mathrm{A}}$ & $9,0^{\mathrm{B}}$ \\
Açúcares, mg/dl & $41,6^{\mathrm{AB}}$ & $37,9^{\mathrm{B}}$ & 4,7 & $38,4^{\mathrm{B}}$ \\
Aminoácidos, mg/dl & 27,6 & 27,5 & 28,2 & 28,6 \\
Peptídeos, mg/dl & 35,9 & 32,6 & 30,2 & 3,2 \\
pH & $7,04^{\mathrm{A}}$ & $6,98^{\mathrm{A}}$ & $6,71^{\mathrm{B}}$ & 16,6 \\
\hline
\end{tabular}

${ }^{1}$ Médias seguidas de letras diferentes na mesma linha diferem pelo teste de Tukey ao nível de 5\% de probabilidade do erro Tipo I.

${ }^{2}$ Desvio padrão das médias, onde $n=4$ por tratamento. 
A relação entre os parâmetros ruminais e o tempo ao longo de um ciclo de 24 horas é apresentada na figura 1. Não houve interação entre tempo e tratamento para estas variáveis e, deste modo, a figura 1 apresenta a variação média de todos os tratamentos. $\mathrm{O}$ pH variou cubicamente $(\mathrm{P}<0,01)$ e os teores de amônia, açúcares e aminoácidos variaram de forma quadrática ao longo do dia $(\mathrm{P}<0,01)$. As concentrações ruminais de amônia e aminoácidos aumentaram após o pastejo e suplementação e as de açúcares foram baixas durante o intervalo de tempo entre o pastejo e a suplementação e aumentaram após a suplementação.

A variação das concentrações de peptídeos não se ajustou a nenhuma das linhas de tendência testadas $(\mathrm{P}>0,05)$. Gramíneas de inverno têm altos teores de compostos nitrogenados solúveis, os quais são rapidamente fermentados no rúmen, determinando aumentos gradativos nas concentrações ruminais de amônia e aminoácidos nas primeiras horas após a ingestão destas forragens. No entanto, logo após a suplementação, os teores de açúcares no rúmen tenderam a aumentar e os de amônia e aminoácidos a diminuir. À medida que aumentou a disponibilidade de carboidratos não estruturais para as bactérias, é provável que, por um lado, tenha aumentado a liberação de açúcares no fluido ruminal e, por outro, tenha aumentado a captação e utilização do $\mathrm{N}$ pela flora microbiana. A atividade fermentativa ruminal parece ser limitada se os teores de amônia são menores que $5 \mathrm{mg} /$ dl (SATTER \& SLYTER, 1974) e/ou se o pH for abaixo de 6,0 (MOULD \& ORSKOV, 1983). No presente experimento, com exceção de alguns poucos horários do dia, os níveis de amônia e o pH ruminal foram sempre superiores a esses valores.

\section{CONCLUSÕES}

A suplementação com sorgo não afeta o ganho de peso dos novilhos mantidos em pastagem cultivada de clima temperado. No entanto, a adequação de horários de pastejo e de suplementação pode representar um fator condicionante à eficiência do uso do suplemento pelos animais.

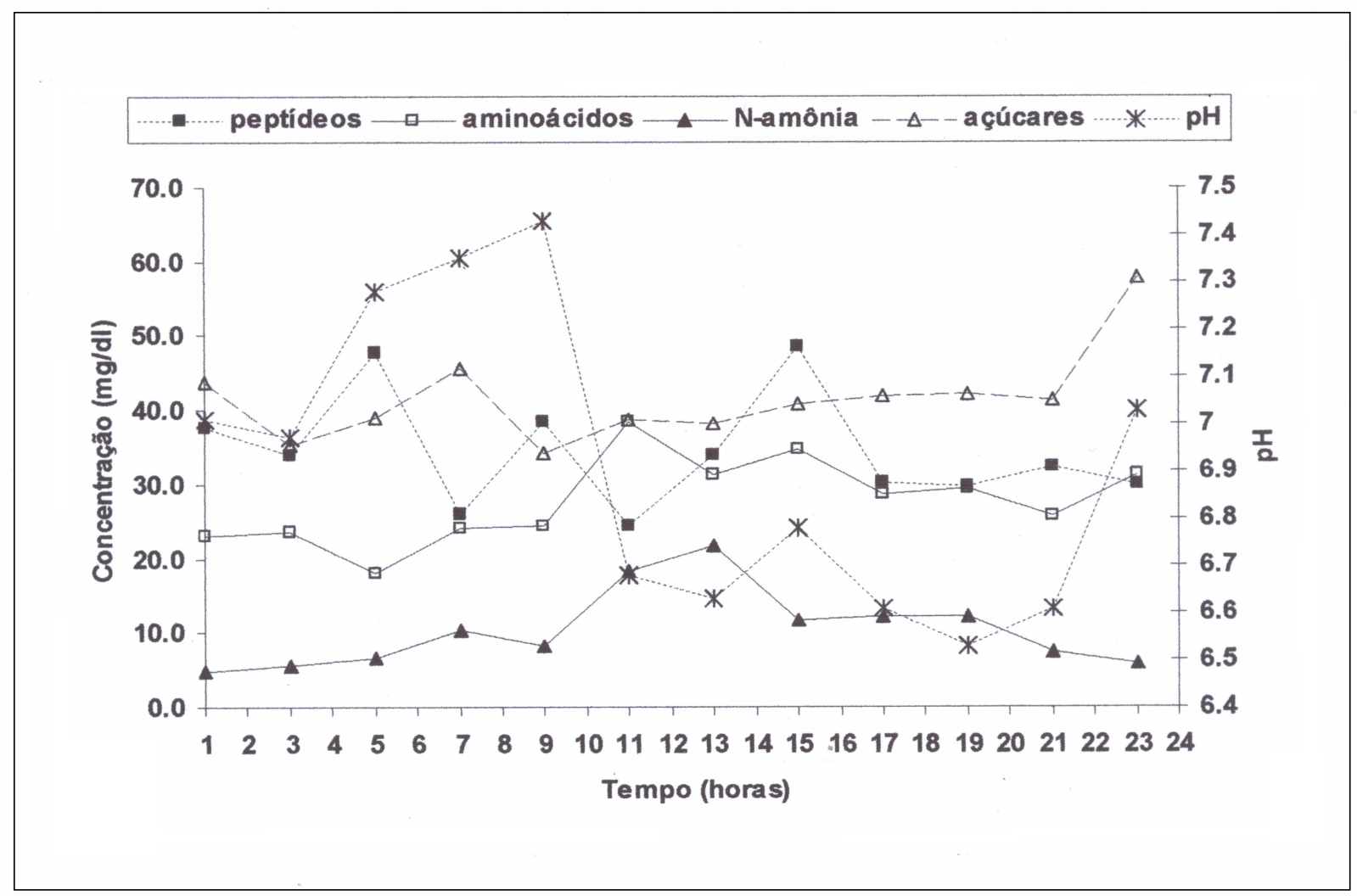

Figura 1 - pH e concentrações de nitrogênio amoniacal, açúcares, aminoácidos e peptídeos (mg $\mathrm{dl}^{-1}$ ) no fluído ruminal, ao longo de um período de 24 horas, em novilhos pastejando aveia + azevém e recebendo ou não suplementação energética. Suplementação fornecida às 14 horas.

Ciência Rural, v.36, n.3, mai-jun, 2006. 


\section{AGRADECIMENTOS}

Os autores agradecem à Coordenação de Aperfeiçoamento de Pessoal de Nível Superior (CAPES) e ao Conselho Nacional de Desenvolvimento Científico e Tecnológico (CNPq) por uma bolsa do Programa de Absorção Temporária de Doutores (PRODOC/CAPES) e pelas bolsas de iniciação científica e de pós-graduação.

\section{REFERÊNCIAS}

AOAC. Official methods of analysis. Washington: Association of Official Analytical Chemists, 1995. 1094p.

BRONDANI, I.L. et al. Silagem de grão úmido para bovinos. In: RESTLE, J. Eficiência na produção de bovinos de corte. Santa Maria: UFSM, 2000. Cap.7, p.205-219.

BRONDANI, I.L. et al. Desempenho de vacas em pastagem cultivada de inverno suplementadas com grão de sorgo ou silagem de milho. In: REUNIÃO ANUAL DA SOCIEDADE BRASILEIRA DE ZOOTECNIA, 40., 2003, Santa Maria, RS. Anais... Santa Maria: SBZ, 2003. (CD-Room).

CATON, J.S.; DHUYVETTER, D.V. Influence of energy supplementation on grazing ruminants: requirements and responses. Journal of Animal Science, v.75, p.533-542, 1997.

CHALKLING, D., BRADESCO, R. Ensilaje de grano húmido: una alternativa promisoria. Uruguay: Mastergraf, 1997. 47p.

DUBOIS, M. et al. Colorimetric method for determination of sugars and related substances. Analytical Chemistry, v.28, p.350-356, 1956

KOZLOSKI, G.V. et al. Potencial nutricional assessment of dwarf elefhant grass (Pennisetum purpureum Schum. cv. Mott) by chemical compositiom, digestion and net portal flux of oxygen in cattle. Animal Feed Science Technology, v.104, p.29-40, 2003.

LICITRA, G. et al. Standartization of procedures for nitrogen fractionation of ruminant feeds. Animal Feed Science Technology, v.57, p.347-358, 1996.
LOWMAN, B.G. et al. Condition scoring of beef cattle. Edinburgh: East of Scotland Colledge of Agriculture, 1973. 8p.

MOULD, F.L.; ORSKOV, E.R. Manipulation of the rumen fluid $\mathrm{pH}$ and its influence on cellulosis in sacco, dry matter degradation and the rumen microflora of sheep offered either hay or concentrate. Animal Feed Science Technology, v.10, p.1-14, 1983.

PALMER, D.W.; PETERS Jr., T. Automated determination of free amino groups in serum and plasma using 2,4,6 trinitrobenzene sulfonate. Clinical Chemistry, v.15, p.891-901, 1969.

RUSSEL, J.B. et. al. A net carbohydrate and protein system for evaluating catlle diets: 1. Ruminal fermentation. Journal of Animal Science, v.70, p.3551-3561, 1992.

ROBERTSON, J.B.; VAN SOEST, P.J. The detergent system of analysis. In: JAMES W.P.T.; THEANDER, O. The analysis of dietary fibre in food. New York: Marcel Dekker, 1981. p.123-158.

SAS. Statistical Analysis System. Software, Version 8. Cary, 1996. CD-ROM

SATTER, L.D.; SLYTER, L.L. Effect of ammonia concentration on rumen microbial protein production in vitro. British Journal Nutrition v.32, p.199-208, 1974.

VANZANT, E.S. et.al. Influence of level of supplementation and type of grain in supplements on intake and utilization of harvested, early-growing-season bluestem-range forage by beef steers. Journal of Animal Science, v.68, p.1457-1467, 1990.

WEATHERBURN, M.W. Phenol-hypoclorite reaction for determination of ammonia. Analytical Chemistry, v.39, p.971-974, 1967.

WEISS, W.P. et al. A theoretically-based model for predicting total digestible nutrient values of forages and concentrates. Animal Feed Science and Technology, v.39, p.95-110, 1992.

ZEOULA, L.M. et al. Solubilidade e degradabilidade ruminal do amido de diferentes alimentos. Revista Brasileira Zootecnia, v.28, p.898-905, 1999 